\title{
EL PENSAMIENTO RELIGIOSO DE F. SAVATER
}

\section{THE RELIGIOUS THOUGHT OF F. SAVATER}

\author{
Miguel Grijalba UCHE* \\ UNED
}

Resumen: En el presente trabajo se presenta el pensamiento en materia religiosa de Fernando Savater. Savater es un autor que se define crédulo más que creyente, ante las sorpresas del pasado o de lo que esté por venir. Rechaza tanto la imposición de una verdad absoluta trascendente, al igual que muestra rechazo a las posturas escéptica o relativista. Para él, el origen de las creencia es el deseo: miedo a morir y el deseo de inmortalidad. Su noción de laicismo supone la concepción de una separación Iglesia y Estado, pero también la ausencia de todo fundamento prepolítico que condicione nuestra ciudadanía. De ahí la necesidad de explicar qué es el laicismo desde una asignatura como Educación para la Ciudadanía

Palabras Clave: laicismo, ciudadanía, creencia, iglesia, educación, Estado.

АвsтRACт: The present work presents Fernando Savater's thinking on religious matters. Savater is an author who defines himself as credulous more than as a believer, faced with the surprises of the past or of what may come. He rejects both the imposition of an absolute transcendent truth and the sceptical or relativistic positions. For him, the origin of belief is desire: fear of dying and the desire for immortality. His notion of laicism involves the conception of a separation between Church and State, but also the absence of any prepolitical foundation that determines our citizenship. Thus, the need to explain what laity is in a subject such as Education for Citizenship.

\footnotetext{
" Miguel Grijalba Uche. C/Progreso n³0-1ºB. 09002. Burgos. E-mail: mgrijalba2003@ yahoo.es
} 
KeYwORDs: laicism, citizenship, belief, church, education, state

\section{Introducción}

Savater considera que no debemos olvidar que muchas de las cuestiones de las que se ocupan las doctrinas religiosas son también temas tradicionales de la filosofía, aunque tomadas en sentido un laico. Luc Ferry definía la filosofía como el intento de asumir las cuestiones religiosas de un modo no religioso. De hecho, Feuerbach consideraba que la religión, sin ningún tipo de filosofía, era idolatría. El discurso de Savater es inmanente, optando por explicaciones naturales (Revilla 2002, 441). Savater no cree que los ateos no se hayan planteado la cuestión de lo último, pero con la diferencia de que intentan acotar intelectualmente qué es lo último (Savater 2007a, 16). La pregunta es si cabe un discurso religioso en un ateo practicante, como se define Savater (Revilla 2002, 421). Para Savater, la verdad de la religión pertenece al orden de lo comprobable, al modo del racionalismo spinoziano (Revilla 2002, 435). Él apuesta por un humanismo sin trascendencia, lo cual no significa rechazar un sentimiento religioso o una receptividad de lo sagrado que no es la habitual del cristianismo (Revilla 2002, 422). Tilda a los creyentes de antiilustrados contrarios a la verdad y defiende una autosuficiencia de la razón (Revilla 2002, 442). Frente al humanismo cristiano de piedad y compasión, Savater propone un humanismo vitalista (Nogueroles 2013, 309). Un humanismo laico que defienda los intereses civiles, tanto de creyentes como de no creyentes (Savater 1998, 71). Y este humanismo es compatible con el pesimismo ilustrado que se deriva de la aceptación trágica de la realidad (Savater 1987, 194).

Pero, en este siglo XXI, tras Darwin, Nietzsche o Freud, tras el desarrollo científico y tecnológico de los últimos ciento cincuenta años, sigue persistiendo el fenómeno de la creencia religiosa incluso entre los científicos más destacados. Se habla también de un regreso de los radicalismos religiosos (la yihad, el auge de los teocons, el terrorismo de Al Qaeda, las guerras de Afganistán e Irak, el revival de la ortodoxia católica de la mano de papas como Juan Pablo II, las manifestaciones dogmáticas de la Conferencia Episcopal española acerca de la ley del matrimonio homosexual, la escuela laica, el aborto...). Es decir, frente a la ilustración racionalista, en pleno siglo XXI (cuando Flores D’Arcais afirma 
que ya lo sabemos todo científica y tecnológicamente ${ }^{1}$ ) la religión sigue presente $y$, en ocasiones, de modo agresivamente presente.

Savater no se considera creyente ni considera que los creyentes crean, sino que creen que creen. Por el contrario se considera crédulo ante lo improbable, ante las sorpresas de lo real y lo que ha pasado o en lo desconcertante que puede llegar a pasar (Savater 2003, 150). Nunca padeció una crisis religiosa como tal, incluso llegó a pasar por una etapa de interés por el politeísmo clásico. Nunca ha sido religioso aunque le gustan los autores religiosos: Lucero, León Bloy, Chestov, Benjamín, Fontane (Barnatán 1984, 74).

\section{Savater y la creencia religiosa}

El primer punto es aclarar qué es eso que llamamos creer o creencia, afirma Savater. Ortega distinguía entre ideas y creencias. Una idea es una construcción intelectual nuestra y, por tanto, nos decía que tenemos ideas. Una creencia, por otro lado, es una certeza que damos por descontada, por lo cual, estamos en una creencia. Las creencias, a diferencia de los hechos, no son ni verdaderas ni falsas: se está en ellas o fuera de ellas (Savater 2004, 55). Creer es asumir que un determinado estado de cosas se da en la realidad, poseer una perspectiva privilegiada que revele el fundamento del mundo y al que otras formas de conocimiento sólo lo atisban superficialmente (Savater 2007a, 148).

Creer es sentirse unido con algo, es un modelo de abstracción. Dios no explica nada en el orden material de las cosas, pero tampoco la ciencia puede explicar por qué hay lo que existe o si tiene algún sentido comprensible para nosotros ${ }^{2}$. Para Savater, siguiendo a Hume, creer o tener mentalidad religiosa es considerar que la comprensión religiosa de la realidad es anterior a la comprensión científica

\footnotetext{
${ }^{1}$ Para Flores D'Arcais, después de Hume y de Darwin ya lo sabemos todo: no existe Dios ni la inmortalidad del alma, somos simios modificados, venimos del Big Bang y vamos hacia la nada.

${ }^{2}$ Savater, Fernando, "La vacante de Dios”, El País (10/09/2010).
} 
(Savater 2007a, 77). Como respuesta, siempre la indiferencia es superior a la fe dogmática, siempre la duda es mejor que la afirmación absoluta que renuncia a toda iniciativa personal (Savater 2007a, 183).

La fe puede tener un cierto tónico en nuestro conocimiento, pero sustituye las pruebas por una inclinación sin razones. Los conocimientos verificables suelen ser deficientes y puede ser precisa una cierta fe para lanzarse a la acción. Pero el crédulo siempre está dispuesto a aceptar lo inverosímil, lo raro o lo conveniente para él. Rechaza el esfuerzo de comprobación y confirmación. Por lo tanto, lo característico de la credulidad es su carácter acrítico y su fondo siempre interesado (Savater 2007a, 184).

Hay quienes justifican las creencias en lo sobrenatural por su utilidad social de calmante de los desasosiegos humanos, o que estiman el papel de la religión por su carácter de estupefaciente (Marx), o por ser el fundamento de la moral o aglutinante de una colectividad, en donde el interés individual se supedita a los intereses de la comunidad. En última instancia, son llamadas del papel de la religión como paliativo de la desestructuración social y pérdida de valores, presentándose a la Iglesia como institución de regeneración espiritual de la humanidad. Para Savater, se cumple una petición de principio en este enunciado. La religión se convierte en un concepto tan amplio que podría servir como gran principio unificador, abstracto e ideal. Por tanto, la religión hace la cohesión y vertebración social sólo porque estamos dispuestos a llamar religión a todo lo que sirva para cohesionar y unir a las comunidades (Savater 2007a, 158). Pero es difícil, para Savater, aceptar una argumentación que proceda de la Iglesia, la cual ignora el desarrollo histórico del pensamiento y las transformaciones radicales y espirituales de la sociedad, que no analiza las causas de los enfrentamientos, cuando no apoya las actitudes más dogmáticas que bloquean cualquier tipo de avance en ella. Por ello es cohesión hacia dentro de sociedades hegemónicas y enfrentamiento hacia fuera, ya que introducen una exigencia de verdad que el politeísmo no conocía. La aceptación de nuestra precariedad es lo que impulsa a pensar en la existencia de Dios (Revilla 2002, 440). 
De modo similar, Savater rechaza una postura escéptica (que debilita la convicción de que podamos nosotros alcanzar esa verdad con nuestra razón). Es la postura de la sofística (nada es verdad, todo está permitido) a la cual también se opone Comte-Sponville. Para Savater, el escepticismo en sí mismo es contradictorio debido a que el escéptico da por segura y fiable la creencia en su propio escepticismo. Pero esto no deja de ser una verdad: si es verdad que no conocemos la verdad, al menos ya conocemos una verdad (Savater 2004, 57-58).

También el relativismo (que niega la verdad fuera de una determinada tradición, con lo cual seremos incapaces de alcanzar la verdad mediante razonamiento) es atacado por Savater por artificioso e insostenible ya que resulta incompatible con nuestra vida cotidiana (Savater 2004, 60). Según esta postura, es imposible llegar en asuntos morales o religiosos a ninguna forma de objetividad inobjetable, ya que los valores están condicionados antropológica y sociológicamente. Aunque el intento relativista sea el de conseguir un pluralismo axiológico, para Savater lo que se consigue es neutralizar toda posibilidad de compromiso moral a escala universal (Savater 2007a, 209). Savater considera que lo razonable no es únicamente la mera subjetividad, sino que también se acepten parámetros sometidos a verificación intersubjetiva. Incluso para determinar hasta qué punto nuestros conocimientos se impregnan de subjetividad, o para desconfiar de los criterios universales de razón y de verdad, precisamos de una razón y una verdad que nos sirvan de criterio universal.

Cabría hablar de una última postura opuesta a la razón y que es la de aquellos que creen en una verdad absoluta e indiscutible que nos ha sido revelada bien a través de maestros sobrehumanos (dioses, ancestros inspirados, guías espirituales...), bien porque se nos manifieste en alguna forma privilegiada de visión o bien porque sólo sea alcanzable a través de intuiciones no racionales, sentimientos, pasiones. Obviamente estos partidarios atacarán a la omnipresencia de la razón y a la labor de los racionalistas, ya que esta verdad absoluta es irrefutable y todo intento de cuestionarla se debe a que el incrédulo carece de la iluminación necesaria para su disfrute, ya por impiedad, ya por embotamiento de las emociones. Pero la razón no exige nada para funcionar (fe, preparación espiritual, pureza de alma, sentimientos): sólo exige ser usada. Si no queremos que los dioses, o ciertos hombres privilegiados, usurpen la autoridad social, nos 
afirma Savater, debemos someternos a la autoridad de la razón como vía hacia la verdad (Savater 2004, 66).

Por otro lado, el nihilismo, según Savater, lo que niega es el derecho de Dios a existir, no su existencia (Savater 1970, 43). El ateísmo es la negativa a aceptar el derecho de la omnipotencia a hacer el mal y el del orden pasado de cosas a determinar el porvenir. Rechaza toda doctrina que legalice los males presentes o preconice nuevos dolores como medio para librarse de los antiguos. Por eso el ateo no puede ser progresista, ya que si avanzamos hacia lo bueno eso significa que el presente se justifica como vía necesaria para el porvenir (Savater 1970, 45). Según Savater, el nihilista considera que el ateísmo es condición imposible, pero a la vez necesaria, vigilando y denunciando a quienes se acogen a algunas de las revelaciones laicas de Dios. La ciencia se presenta como otra divinidad, otro dios menor, en donde el discurso significativo es el que versa sobre los hechos y el sentido de los hechos es inefable (Savater 1970, 49). El verdadero ateísmo es el que desecha la fe en la total inteligibilidad del mundo (Nogueroles 2013, 96).

Ningún Dios inteligente y personal es ajeno al vínculo con los hombres. Este vínculo, en los humanos, responde a una necesidad de mutuo apoyo. Esta es la apuesta de toda religión: Dios como rector y garante de la rectitud moral de los hombres, los cuales se comprometen en acatar sus leyes, y esperan su correspondiente premio o castigo según la conducta, en el más allá que es de pleno dominio divino. Si Dios ha muerto se puede decir que el mal en el mundo ha desaparecido definitivamente, que la finitud ha sido vencida y el hombre ha encontrado al fin el paraíso (Savater 1970, 25). Bien es cierto que existen males éticamente neutros que sólo lo son para nosotros (enfermedades, catástrofes). El problema son los males cuando atacan a los más desvalidos: niños, la vejez, los desahuciados...Pero, a ello, debemos ańadir los males que corresponden a una perversidad intencionada: tortura, esclavitud, tiranía, matanzas indiscriminadas, abuso de explotadores, campos de exterminio. En todo ello aparece la mediocridad del hombre, su miseria, que nos hace sumamente incompatibles con su origen divino. Dios debería impedir estos males, en lugar de penalizarlos. 
Muchas veces se habla de respeto a las creencias cuando en realidad se trata de miedo. Cada uno puede cultivar su verdad religiosa privada, pues la religión es algo íntimo. Puede expresarse públicamente, pero a título privado, arriesgándose a críticas e irreverencias. Planteada esta cuestión, la siguiente pregunta es: ¿dónde radica la verdad de las creencias? La religión es aceptada culturalmente, por tradición simbólica y ritual, siempre llena de implicaciones morales (Savater 1990, 197). Y nadie puede negar la relevancia cultural, antropológica, moral y política de las doctrinas religiosas.

Aquí nace la pregunta de Savater, ¿por qué se cree en lo invisible como explicación final de lo visible? W. James consideraba la fe como forma de fundamentar nuestras creencias, las cuales nos orientan e impulsan en nuestra acción en el mundo. Para James lo importante no es de dónde vienen esas creencias sino a dónde nos llevan. Esta idea es dudosa para Savater: cuando la diferencia entre lo posible y lo imposible depende de nuestra decisión, la fe será útil en cuanto conciencia de nuestra fuerza. Pero no transforma en posible lo imposible (Savater 2007a, 37). La promesa en una vida eterna, en donde se cumplirán nuestros anhelos, se convierte en el mecanismo para resignarnos a nuestra vida terrenal, eliminada toda reivindicación de nuestro mundo real (Savater 2007a, 87-88).

Una segunda visión es la que considera la fe en Dios como la creencia en un ser invisible, incomparable en esencia a cuanto podemos comprender, narrar o decir. Ante esta situación, no cabe ninguna discusión, objeción ni perplejidad, pero también este discurso queda blindado sobre cualquier duda de su verosimilitud. Toda negación de Dios (desde Feuerbach hasta Nietzsche o Freud) será vista como mera deficiencia humana ante su comprensión (Savater 2007a, 90).

Una tercera visión es la de considerar a Dios como concepto supremo, sin rasgos antropomórficos (con herencia en el demiurgo platónico, el motor inmóvil aristotélico o el Uno de Plotino) que proviene, sobre todo, de Spinoza. La modernidad ilustrada denunció a las supersticiones eclesiales con su racionalismo científico y su inmanentismo, su pretensión de protección social, educación y su internacionalismo (Savater 2007b, 377). La Ilustración ha sido siempre la 
poseedora de un espíritu crítico frente a épocas oscuras donde imperaba la fe de lo inverosímil, la persecución de quien piensa diferente, la rutina o el pánico. Las mayores crueldades, las matanzas más atroces se han realizado por motivos religiosos y con la bendición de la Iglesia (Savater 1993, 178).

\section{Fundamentación de la creencia religiosa}

Para Savater, los deseos son el fundamento personal de las creencias. No nos fundamentan las creencias, por ejemplo, los milagros, siempre procedentes de un ser superior que nos favorece de modo personal y satisface nuestra apetencia privada. Tampoco sirve, como fundamentación, la experiencia religiosa, como señalaban W. James o R. Otto. Nadie tendría experiencias religiosas, nos dice Savater, si previamente no conociera que hay una religión. La mayoría de las personas cree por mímesis social. Así, la base de nuestro deseo de creer está en la conciencia irremediable de nuestra muerte y en el deseo de evitarla, aplazarla o conjurarla (Savater 2007a, 40). De manera que las creencias religiosas son tecnologías de salvación, lenitivo para el padecimiento anticipado de nuestra muerte, aunque exijan alguna verdad sobrenatural que lo garantice.

La muerte es la fulminación única del individuo. La primera reacción es la desesperación como manifestación del instinto de conservación: miedo (lo peor está viniendo siempre hacia nosotros), codicia (todo es poco para quien teme convertirse en nada en cualquier momento) y odio (hacia lo que nos desmiente o lo que aumenta nuestra inseguridad) (Savater 1998, 30-31). De ahí surge la fe en un dios personal que nos rescate de esa muerte, aunque es irreconciliable con el conocimiento cierto de nuestra aniquilación personal (Savater 1998, 34). Quien busca el sentido de la vida sólo lo encuentra en la muerte, ya que reconcilia interior y exterior en unidad inexpugnable (Savater 1995, 37-39). Para Savater, la vida en su conjunto no tiene sentido porque no conocemos las intenciones fuera de las vitales. Por eso, la pregunta por el sentido de la vida carece de sentido. Lo absurdo no es que la vida carezca de sentido sino preguntarse por el sentido de la vida (Savater 2004, 272-274). 
El deseo de inmortalidad no sólo es un deseo humano, sino también humanizador. Afirma Savater que casi todo lo que hacemos lo hacemos para evitar o resistir morir. Si no existiera la muerte, habría mucho que ver, aprender y mucho tiempo para verlo y aprenderlo, pero muy poco que hacer y nada en que pensar. El hombre mira a su alrededor y deduce que si todo muere, ¿por qué no va a morir él? La pregunta, en Savater, no es tanto si hay vida tras la muerte sino si hay vida antes de ella. Si hubiera vida después no sería en sí misma una vida o también generaría el miedo a morir en esa vida (Savater 2004, 38). Paradójicamente, lo que caracteriza a los creyentes no es aquello en lo que creen, sino en lo que no creen: en la muerte. Savater los considera incrédulos ya que niegan la realidad última de la muerte. El ser humano siempre ha considerado la esperanza de que la extinción física del cuerpo no acabe con nuestras ideas, emociones o nuestra autoconciencia. Por eso afirma Savater que la muerte nos hace pensar pero no sobre ella, sino sobre la vida misma. Frente al aturdimiento, que no quiere mirar la muerte, o la angustia que mira pero nos deja cegarnos estremecedoramente por ella, hay una alternativa mortal que es la de intentar comprender la vida (Savater 2004, 43).

\section{Religión, Iglesia y Savater}

El marco institucional secular protege, en vez de perseguir, a las creencias religiosas. Las religiones pueden dictar qué conductas son pecado pero no pueden decir qué conductas son delito. Son las religiones quienes deben acomodarse a las leyes. Una cosa es garantizar el derecho de elegir su forma de vida y otra es que tradiciones religiosas contrarias a los derechos de las constituciones democráticas no se puedan combatir por leyes. Es la falacia del multiculturalismo (Savater 2007a, 138). Así, en España, gran parte de la jerarquía católica consideran que se les persigue cuando se les cercena la capacidad de perseguir. Ahora se exige que la Iglesia mantenga todos sus privilegios teocráticos de la época pasada o que incluso pueda decidir qué tipo de valores cívicos deben ser enseñados en la escuela, so pena de sublevar a la feligresía clamando contra la persecución religiosa ${ }^{3}$. Las creencias son un derecho de cada uno pero no un deber de nadie ni de las instituciones públicas ${ }^{4}$. La intransigencia eclesial durante siglos tuvo que

\footnotetext{
${ }^{3}$ Savater, Fernando, “¿El final de la cordura?”, El País (3/11/2008).

${ }^{4}$ Savater, Fernando, "Fanáticos sin fronteras”, El País (11/02/2006).
} 
remitir cuando disminuyó su peso católico a nivel social y pasó de ser obligación de todos a ser devoción privada de algunos ${ }^{5}$.

Se ha dado un giro ideológico en donde si se debilitan los razonamientos políticos, se refuerzan políticamente las creencias religiosas. Los colectivos socialmente más influyentes recuperan la voz teológica para justificar sus intervenciones públicas. El respeto se da en rasgos no elegidos (color de piel, edad o minusvalía) pero no es exigible democráticamente en opciones personales, sino que hay que resignarse a la crítica e incluso a las bromas. Ninguna creencia es incompatible con la democracia, sólo hay que domarla para que renuncie a su teocracia ${ }^{6}$. El peligro está en convertir en enemigos a cuantos no comparten nuestra fe ${ }^{7}$.

Savater también rehúsa el calificativo de ateo porque es un término religioso. Savater es anticlerical en cuanto que rechaza a mediadores que mantienen una relación distinta con el espíritu que los demás. Quizá es más sugestivo el abandono de las religiones que la refutación de las iglesias ${ }^{8}$. La iglesia manifiesta odio por la libre indagación de todo lo que independiza. Considera que el librepensamiento es un pecado a extirpar. Por eso, la Iglesia Católica ha condenado sistemáticamente la autonomía moral de la persona y la libertad de conciencia (Savater 2007a, 190). El valor y la dignidad de la vida está en manos de los hombres ya que los hombres son los únicos que deben afrontar su condición trágica: heteronomía moral, fanatismo, hipocresía, negación del cuerpo y apología del poder jerárquico ${ }^{9}$. No hay posibilidad de reconciliación ni de salvación ni de legitimación trascendente ${ }^{10}$.

\footnotetext{
${ }^{5}$ Savater, Fernando, "Regreso al futuro", El País (28/05/2008).

${ }^{6}$ Savater, Fernando, "Otras inquisiciones", El País (19/01/2004).

7 Savater, Fernando, "Los santos terribles", El País (1/07/2008).

${ }^{8}$ Savater, Fernando, "Iglesia y religión", El País (14/06/2011).

9 Savater, Fernando, “Osadía clerical”, El País (21/03/1980).

${ }^{10}$ Nogueroles, Marta. Fernando Savater. Biografía intelectual de un joven filósofo. Madrid, Endimión, 2013, p. 215.
} 
El poder eclesial es una seria amenaza para la consolidación de la democra$\mathrm{cia}^{11}$. Para Savater, no existe institución más nefasta en toda la historia moderna de España que la Iglesia católica que es oscurantista, oportunista y dogmática El ateísmo de Savater tiene que ver menos con su militancia y más con su protesta ante la vinculación de la Iglesia española con el poder estatal ${ }^{12}$. Es inadmisible, igualmente, el monopolio de la educación y de la enseńanza privada en nombre de la libertad de enseñanza que le fue concedido durante la dictadura de Franco. De ahí que la Iglesia se inmiscuya en cuestiones de Estado como el divorcio o la ley del aborto, y que se haga en nombre de una supuesta ley natural y en defensa de la familia ${ }^{13}$. El Concordato lo que mantiene es la sumisión cívica del Estado español, que debería ser laico ${ }^{14}$. Savater afirma que continuará escribiendo en defensa del laicismo como condición indispensable de la democracia y que su oposición no es tanto a la religión sino a quienes imponer sus ideas religiosas a los demás ${ }^{15}$

El tema central del libro Escritos politeístas de F. Savater es el monoteísmo y las nefastas consecuencias que ha tenido para la humanidad (Nogueroles 2013, p.58). Por ello, Savater hace suyo el sueño del eterno retorno del politeísmo pero purificado por la profunda experiencia del nihilismo monoteísta (Savater 1975a, 109). En la época en que los dioses dominaban el mundo en comunidad perfecta, éstos eran felices y mostraban la irrelevancia de la virtud o de la reprobación del vicio. El monoteísmo supuso la caída, a partir de la cual nació la abstracción y, de ella, el Estado (Savater 1975a, 23). El politeísmo exigía piedad frente a fe. Una piedad práctica, que no necesita demostraciones, que provoca el desencadenamiento de las pasiones (Revilla 2002, p. 431). Savater reivindica un pensamiento negativo que no se rinde ante un sistema reinante que niega la evidencia del mal. Supone, por tanto, el rechazo al sistema hegeliano y al monoteísmo subyacente. De ahí que reivindique la acción, desde nuestra condición finita y negando la necesidad, que nos oriente hacia una ética del querer y no del deber, autónoma y ateológica (Revilla 2002, 426). Este proyecto ético es de la inmanencia, de ahí

\footnotetext{
${ }^{11}$ Nogueroles, Marta. Fernando Savater. Biografía intelectual de un joven filósofo. Madrid, Endimión, 2013, p.205.

${ }^{12}$ Savater, Fernando, "Osadía clerical”, en El País (21/03/1980).

${ }^{13}$ Savater, Fernando, "Osadía clerical”, en El País (21/03/1980).

${ }^{14}$ Savater, Fernando, "Batalla de catecismos”, El País (9/12/2013).

${ }^{15}$ Nogueroles, Marta. Fernando Savater. Biografía intelectual de un joven filósofo. Madrid, Endimión, 2013, p. 210.
} 
el rechazo de Savater por las éticas religiosas ya el su fundamento, Dios como salvador, nos priva de libertad (Revilla 2002, p. 428). Por inmanencia entiende el rechazo a buscar explicaciones que las convierta en fundamento trascendente, de ahí la importancia del azar (Revilla 2002, 436). La ética de Savater es laica y universalista (Nogueroles 2013, 361).

Luchar por cambiar el Estado está relacionado con el anhelo de libertad y con la recuperación de los dioses paganos como reductos de una renovada fe, según Savater. Las características del politeísmo son el primado de lo abierto, de lo plural, del respeto a lo diferente (Savater 1975a, 57). El cristianismo, por el contrario, instaura el dominio de la decadencia y el rechazo de la vida (Savater 1975a, 108). La abstracción monoteísta tiene tres nombres: el Estado, el Hombre, la Naturaleza. Cada nombre de Dios tiene su ley: Constitución civil, Moral, Leyes naturales. Y siempre exigen la fe en la igualdad invisible: ante la ley, ante las pasiones, etc (Savater 1975b, 17). El Dios monoteísta es Dios de justicia, que se manifiesta en la ley cuyas normas son universales y abstractas que desprecian la diversidad (Savater 1975b, 16-17). La propuesta politeísta, por el contrario, es una propuesta contra el poder centralizado, a favor de la anarquía y donde sólo la ética puede devolvernos al ámbito de lo sagrado, de la insumisión (Nogueroles $2013,101)$. Frente a la concepción lineal del tiempo cristiana, Savater propone el eterno retorno de los ciclos que nos acerca al no-tiempo de lo sagrado ${ }^{16}$. Lo sagrado, en Savater, se localiza más allá de la ética, trasciende lo inmediato y solicita piedad ante el sufrimiento humano (Revilla 2002, p. 428). Lo sagrado se reduce a una autocompresnión de lo existencial (Revilla 2002, 443). Es lo opuesto al poder, por eso la auténtica revolución consiste en recuperar lo sagrado (Nogueroles 2013, 99), ya que el monoteísmo supuso la pérdida de lo sagrado y la culminación del proceso de abstracción (Savater 1976, 73).

\section{Las raíces cristianas de Europa}

Si hablamos de raíces cristianas de Europa debemos recordar que el cristianismo originario introdujo el vaciamiento secular de lo sagrado, separando

\footnotetext{
${ }^{16}$ El intento más moderno de recuperar la teoría del tiempo cíclico es la Ciencia Nueva de Vico, en la cual se revoca el planteamiento lineal del tiempo, según Savater,
} 
a Dios del César y a la fe de la legitimación estatal. Por ello, las antiguas raíces cristianas deberían considerar no sólo a los antiguos cristianos, sino también a los agnósticos e incrédulos posteriores que combatieron al cristianismo convertido en nueva idolatría estatal ${ }^{17}$. Las raíces cristianas de Europa tienen su expresión en la ciencia que aniquila leyendas piadosas, en la separación del poder secular y las injerencias clericales, en la proclamación de los derechos humanos, en la educación oficial que se niega a oficializar a las creencias religiosas o la autoridad de los obispos ${ }^{18}$.

Lo sagrado es lo que no se puede tocar, pero sin que tenga una proyección trascendente. Santificar significa separar, seleccionar y purificar. Por eso lo sagrado es un orden frente a un caos, como victoria frente a la muerte pero vinculado al reino de la necesidad (Savater 1977, 25). En La piedad apasionada define la necesidad como lo que nos constrińe, ya que lo necesario es la muerte (Revilla 2002, 432). El problema es que lo sagrado se ha visto invadido por lo religioso como si la religión resguardase a la ética sobre lo que está bien o no, sobre lo que puede hacerse o no (Ávila 2006, 45). En Invitación a la ética lo sagrado se localiza más allá de la ética, aquello de lo que brota la imaginación creadora (Revilla 2002, 434). En este libro, Savater le otroga a lo sagrado una dimensión política pues se trata de un concepto que se enfrenta a la muerte y necesidad ${ }^{19}$

Cuando en la Constitución europea se intentó hablar de las raíces cristianas de Europa, la actitud más prudente era haber apelado a lo que nos une y no a lo que nos separa. Pues el choque de civilizaciones es más bien un enfrentamiento entre ideologías teocráticas opuestas en Europa. La mención del origen cristiano en la Constitución europea era una forma de reforzar el peso político de las iglesias en nuestras instituciones.

\footnotetext{
${ }^{17}$ Savater, Fernando, "Laicismo: cinco tesis", El País (3/04/2004).

${ }^{18}$ Savater, Fernando, "Nuestras raíces cristianas", El País (4/07/2003).

${ }^{19}$ Savater, Fernando. Invitación a la ética, op. cit., p. 130.
} 
Benedicto XVI, en su discurso de Ratisbona, habló de la confluencia entre fe bíblica y filosofía griega, de la que brota lo que hoy llamamos Europa, olvidando la idea de la jurisprudencia romana en este aspecto. Los griegos nunca hablaron de verdad o falsedad en el terreno religioso. Ese fue un rasgo monoteísta. El Papa confundió lo racional, como comprensible por la razón, con racional como dirigido por la razón, que es la acepción que a él le interesa. Pero es más fácil que los humanos nos entendamos a partir de la razón que a partir de la fe porque la razón es común y las creencias son particulares, irracionales, fuente de superstición y obediencia (Revilla 2002, 437). Las religiones se configuran como amenazas relevantes a la forma de encontrar formas de convivencia entre grupos diferentes. Y se suma a la falta de instrumentos intelectuales en la sociedad europea para combatir los dogmatismos de las iglesias, que sólo coinciden en el aborrecimiento del laicismo democrático. La verdad de las afirmaciones religiosas proviene de la revelación y su interpretación depende de un cuerpo de especialistas (Revilla 2002, 438). La secularización y la incredulidad tienen un origen cristiano como denuncia de la religión establecida como culto legitimador del poder terrenal ${ }^{20}$. Pero lo realmente cristiano es la denuncia de la injerencia de la religión como culto legitimador de poder terrenal.

\section{El Laicismo}

Se llama religión a la poesía que pretende dar una explicación del cosmos mejor que el método científico. Aspira a dar una explicación sobrenatural a nuestra condición natural y establecer normas de conducta. De modo que la religión se convierte en un ideal obligatorio y nosotros debemos trasformar nuestra experiencia vital de acuerdo a los dictados de esos preceptos ${ }^{21}$. Los creyentes creen tener argumentos trascendentes para rechazar leyes que van en su contra o para que se dicten otras de acuerdo a la normativa divina. Se puede reclamar respeto, pero el papel de las creencias debe estar dentro del marco de la ley, nos dice Savater. Hay enseñanzas religiosas que son incompatibles con la legislación de un país democrático del siglo XXI. Las creencias y prácticas religiosas se amparan en la libertad ideológica reconocida en la Constitución pero siempre que no vayan en contra de las leyes del país (Savater 2007a, 216).

\footnotetext{
${ }^{20}$ Savater, Fernando, "Nuestras raíces cristianas", El País (4/07/2003).

${ }^{21}$ Savater, Fernando, “¿Es tolerable la tolerancia religiosa?”, Isegoría 2008; 39: pp. 22-23.
} 
La laicidad para Savater es reconocer la autonomía de lo político y lo religioso, la separación de la esfera terrenal y el ámbito de las creencias. La liberación es mutua ya que las iglesias dejan de estar manipuladas por los gobernantes. El laicismo es, por tanto, una forma de entender la política democrática y la doctrina de la libertad civil, en donde todos los miembros son iguales con una capacidad similar de participar en la formación y expresión de la voluntad general. El laicismo propone la existencia de modo explícito y razonado de una serie de valores cívicos comunes que dependen de la ética de convivencia en la igualdad. Las creencias son derecho de cada uno, pero no son deberes de nadie y menos de las instituciones públicas ${ }^{22}$.

El laicismo es democráticamente exigible en las instituciones públicas, como las educativas, pero no en las personas individuales. Lo cual no exime del respeto a los códigos de conducta en lugares públicos. Y que las leyes amparen cualquier reclamación que el ciudadano realice contra imposiciones familiares o vejaciones sociales, como el uso de velos o indumentaria islámica ${ }^{23}$. Para Savater, los rasgos de la laicidad son que el Estado vele porque no se imponga ninguna afiliación religiosa o se impida ejercerla a quien la tenga, y el respeto a las leyes del país que deben estar por encima de cualquier religión. En cuestiones de hecho o de derecho no cabe exigir dispensa alguna por razones religiosas. Se puede reclamar respeto, pero nada más.

Por ello, Savater habla de laicidad como estado de cosas o condición, y laicismo como disposición o actitud ante una situación que pretende que el poder político proteja a los ciudadanos de la injerencia del clero. En Espańa se habla de aconfesional pero no es laico porque no tiene una sola devoción religiosa, sino que es multiconfesional, una teocracia politeísta. No debemos olvidar que la enseñanza tiene efectos públicos, que una cosa es la instrucción religiosa que cada cual quiera dar a sus hijos y otra muy distinta es el contenido del temario escolar del Estado. En la escuela pública debe haber elucidación y debate de nuestras normas y objetivos de toda convivencia democrática que se basan en legitimaciones racionales y deben someterse a consideraciones históricas. De igual modo

\footnotetext{
${ }^{22}$ Savater, Fernando, "Del dicho al hecho", El País (28/09/2007).

${ }^{23}$ Savater, Fernando, "Los velos en danza”, El País (27/04/2010).
} 
ocurre en materia de moral y de los valores. Debe exigirse una libertad de crítica en donde permanezca abierta la opción de denunciar la falsedad o nocividad de las creencias religiosas. En ciertas cuestiones, una dosis de intransigencia forma parte insustituible de la salud mental y moral $^{24}$.

El laicismo va unido a una visión republicana del Estado. Y choca con una idea nacionalista porque no hay nación de naciones sino nación de ciudadanos iguales. La Iglesia católica y el nacionalismo son dos poderes fácticos de fundamentación mitológica que consideran persecución totalitaria cualquier merma de sus privilegios autoconcedidos ${ }^{25}$. El primer mandato laicista debe ser romper con la idolatría culturalista y fomentar un espíritu crítico respecto a tradiciones propias y ajenas ${ }^{26}$. La apelación a lo originario o su reestablecimiento (nacionalismo, por ejemplo) sirve para remitirse a una instancia superior que sería trascendente $^{27}$. Por ello, el clericalismo o nacionalismo no puede ser progresista. El estar juntos es una fórmula laica radicalmente compartida y ningún ser hipostasiado puede resultar como factor actual de progreso ${ }^{28}$. Quizá, por eso, en Europa, el Estado más laico que es Francia también es el más unitario en concepción de servicios públicos como en administración territorial ${ }^{29}$.

La tolerancia es la disposición cívica a convivir armoniosamente con personas de creencias diferentes u opuestas, o con hábitos y costumbres que no compartimos. Es soportar lo que nos disgusta. Pero la tolerancia es de doble dirección, es decir, no prohibir la conducta del otro tiene como contrapartida que éste se resigne a objeciones o bromas. Debe cundir la moderación porque lo respetable son las personas no sus opiniones o comportamientos. La tolerancia es el reconocimiento del derecho a no creer y es inseparable del individualismo liberal porque suprime la influencia eclesial sobre leyes y autoridades ${ }^{30}$. La tolerancia es, por tanto, un valor del laicismo (Savater 1976, 87).

\footnotetext{
${ }^{24}$ Savater, Fernando, “¿Es tolerable la tolerancia religiosa?”, Isegoría 2008; 39: p. 26.

${ }^{25}$ Savater, Fernando, “Ciudadanía y lengua común”, El País (11/07/2008).

${ }^{26}$ Savater, Fernando, "La laicidad explicada a los nińos", El País (5/11/2005).

${ }^{27}$ Galindo, Alfondo, "Fernando Savater, entre retórica y política”, op. cit., p. 106.

${ }^{28}$ Savater, Fernando, "Los demonios racionales", El País (21/04/2006).

${ }^{29}$ Savater, Fernando, "Laicismo: cinco tesis", El País (3/04/2004).

${ }^{30}$ Savater, Fernando. "Los requisitos de la tolerancia", El País (22/4/1995).
} 
En el laicismo, la pretensión es salvaguardar la libertad de conciencia cívica frente al libertinaje teocrático ${ }^{31}$. Esperando la llegada de una libertad de conciencia institucional nos ha llegado una laicidad positiva que, aunque respeta la libertad de creer o no, mantiene a las creencias religiosas por ser beneficiosas social y moralmente. El concepto de laicidad debe ser negativo en cuanto que rechaza cualquier injerencia de lo público en las creencias y viceversa ${ }^{32}$. Savater afirma que hay otras formas laicas de religiosidad: el pensamiento científico que intenta ser el único conocimiento, el agnosticismo positivista, etc. Convertidos los dogmas en creencias particulares, pierden su obligatoriedad (Nogueroles 2013, 112).

Ratzinger denunció el laicismo de España pero olvidó los privilegios fiscales o el mantenimiento del Concordato de origen franquista, que impone la presencia clerical en la educación y en el ejército o habla de persecución por un Parlamento cuando éste legisla en materia del aborto o matrimonio homosexual. Para Ratzinger, la verdad no se alcanza por la razón, sino por la revelación. Pero Ratzinger no ha sido el único Papa en opinar de modo semejante. Pío VI en su encíclica Quod aliquantum se mofaba de la igualdad de los hombres. Gregorio XVI en Mirari consideraba la libertad de conciencia un error peligrosísimo. El Syllabus de Pío IX condenaba a la libertad de conciencia. Pío X en Vehementer consideraba falso la separación entre Estado civil e Iglesia porque limitaba la acción del Estado a la felicidad terrena. Hubo que esperar al Concilio Vaticano II y al decreto de Pablo VI Dignitatis humanae personae para que se reconociese la libertad de conciencia contra la cual no vale ni razón de Estado ni razón de Iglesia.

En nuestro país, los representantes electos siguen mostrando todo tipo de deferencia y reconocimiento moral al gobernante del Estado Vaticano como Jefe de Estado y que parece ejemplificar las raíces de la Europa democrática. El Vaticano se trata de un Estado teocrático que incumple abiertamente los derechos humanos fundamentales, como la no discriminación por causa de religión o sexo (Savater 2007a, 246). Se desea un Estado laico en donde la religión, o la falta de ella, sean un derecho de cada cual pero no una obligación para nadie y

\footnotetext{
${ }^{31}$ Savater, Fernando, "El triunfo del libertinaje", El País (8/12/2007).

${ }^{32}$ Savater, Fernando, "Siempre negativa, nunca positiva", El País (16/10/2008).
} 
mucho menos para las instituciones. Ciertas conquistas de la dignidad humana, como los derechos humanos, se hicieron remando en contra de la Iglesia y de sus representantes más distinguidos ${ }^{33}$. Son frecuentes los abusos dogmáticos por instigación clerical que entorpecen el funcionamiento de las democracias, condicionando la vida cotidiana de los ciudadanos. Por eso se hace urgente una ley de libertad religiosa, para que los creyentes puedan ejercer, a título personal, la religión que prefieran sin conculcar las leyes civiles, y que los no creyentes no nos tengamos que sentir avasallados por la fe de nadie ${ }^{34}$.

\section{El papel de la educación con respecto a la religión}

Todas las iglesias deben ser domadas para liberarlas de sus pujos teocráticos. Lo que no encaja son las concesiones a las iglesias, por ejemplo, en materia educativa $^{35}$. Savater cuestiona no tanto el derecho de los padres de dar la instrucción religiosa que deseen a sus hijos, sino la conveniencia de convertir el adoctrinamiento confesional en parte de la preparación de los alumnos, subvencionada por el Estado y gestionada por las autoridades académicas. Los padres tienen derecho a formar religiosa y moralmente a sus hijos, pero el Estado (siguiendo el artículo 27.2 y 27.3 de la Constitución) tiene la obligación de garantizar una educación que desarrolle la personalidad y enseñe a respetar los principios de la convivencia democrática. Por lo tanto, la educación moral no puede ser competencia de los padres sino que corresponde a la sociedad entera. Por ello, resulta abusivo que los niños antes de elegir se les obligue a la religión familiar.

El problema de las doctrinas religiosas, como decía Santayana, es su intervención en cuestiones de hecho. En materia de educación, las explicaciones religiosas son inaceptables porque ningún hecho verificable puede falsarlas (como diría Popper) ni comprobarlas. Se suele decir que lo mismo pasa con la democracia que se basa en principios indemostrables. Pero la democracia no trata de cuestiones de hecho sino de derecho. Por tanto, son verificables de la manera que les es propia. Y lo mismo en la moral en donde no se puede aceptar que los preceptos

\footnotetext{
${ }^{33}$ Savater, Fernando, "La globalización de Dios”, El País (13/04/2005).

${ }^{34}$ Savater, Fernando, “¿Hasta cuándo?”, El País (9/11/2010).

${ }^{35}$ Savater, Fernando, “Otras inquisiciones”, El País (19/01/2004).
} 
éticos sean emanados de una autoridad sobrenatural. Por eso, tolerar cualquier enseñanza en materia de religión no es sólo tolerar cualquier forma de pensar sino cualquier forma de educar para vivir en sociedad ${ }^{36}$.

Las críticas a la asignatura Educación para la Ciudadanía se han centrado en la cuestión del adoctrinamiento indicando que el Estado no puede pretender educar a los neófitos en cuestiones morales ya que se transmitiría, en palabras de Rouco Varela, una forma de ver la vida. Pero la educación tiene la obligación de instruir en valores morales compartidos. Los alumnos deben distinguir entre pecados y delitos, lo que es propiedad de la conciencia y lo que es propiedad de las leyes. Pero lo que es falso es que la moral sea un asunto familiar ya que nadie vive alejado de las interacciones sociales. La ciudadanía es garantía de derechos no ligados a etnia, territorio sobre la que podemos edificar nuestra vida como actores sociales $^{37}$. Para la educación, la religión no es algo íntimo sino que se manifiesta en el espacio público. Pero se inscribe en ese espacio a título privado, aceptando el pluralismo y desvinculándose del ordenamiento político ${ }^{38}$. Debe haber una asignatura de Ética que reflexione sobre el origen, fundamento y necesidad de valores humanos en general y una asignatura de Educación para la Ciudadanía que transmita la exigencia moral de tener valores comunes instituidos legalmente y que sirven de directrices de comportamiento social ${ }^{39}$.

Para la Iglesia, hay un plano moral marcado por su ortodoxia cuyos preceptos marcan la pauta ética en nuestra sociedad. La moral, para Savater, debe ir a favor del hombre, debe ser egoísta y buscar lo mejor para uno mismo que, en definitiva, implica lo mejor para los otros. La ética laica y racional, por otro lado, aspira a una vida humana mejor, mientras que el catolicismo promete algo mejor que la vida y que está en el más allá. No hay ningún criterio interno a la propia religión que permita establecer una moral. Por ello, la ética debe ser laica sin refugiarse en ninguna tradición dogmática eclesial, pero tampoco cívica ${ }^{40}$. La ética laica

\footnotetext{
${ }^{36}$ Savater, Fernando, “¿Es tolerable la tolerancia religiosa?”, Isegoría 2008, 39: p. 25.

${ }^{37}$ Savater, Fernando, "En defensa propia”, El País (12/08/2006).

${ }^{38}$ Savater, Fernando, "Educación cívica: ¿transversal o atravesada?”, El País (1/03/2005).

${ }^{39}$ Savater, Fernando, "Instruir educando", El País (23/08/2007).

${ }^{40}$ Savater, Fernando, “Tres actitudes morales”, El País (18/12/2004).
} 
y humanista hace a las doctrinas religiosas compatibles con la sociedad en que vivimos. Es la religión quien busca apoyo en la ética (Savater 2007a, 190-191).

En 1991 entró en vigor la LOGSE en donde el tema de la ética como alternativa de la religión fue uno de los temas de controversia. Savater defendía la necesidad de su enseñanza en una sociedad democrática pero no como alternativa a la enseńanza religiosa ${ }^{41}$. La educación humanista no puede dejar de transmitir nociones básicas de moral y comportamiento (Savater 2002, 148). La ley Wert actual lo que hace es introducir a la ética, bajo el apelativo de valores éticos, como alternativa y coartada para justificar la introducción del catecismo como asignatura puntuable. En una sociedad abierta, pluralista y laica, no sometida a rigideces teocráticas, las leyes no deben pretender zanjar las divergencias morales entre los ciudadanos, sino crear un ámbito en el puedan convivir todas sin humillación de nadie ${ }^{42}$. Lo chocante es que la asignatura de religión venga obligada por un Concordato realizado con un país que es ajeno al nuestro. Lo que no se entiende es que el Estado espańol mantenga esta relación comprometedora con un Estado que no respeta los derechos humanos ni la igualdad de sexos. El adoctrinamiento confesional no tiene lugar en la enseñanza pública y mucho menos ser pagado por el erario público ${ }^{43}$. Y lo curioso es que quienes pretenden encerrar ideológicamente a los niños sean los que acusan al Estado de totalitario al hablar de valores neutros ${ }^{44}$.

El Consejo Escolar de Estado pidió retirar la asignatura de religión del currículo escolar, que no fuera evaluable a efectos académicos y que no tuviera alternativa en el horario lectivo. Además pidió una ruptura de los Acuerdos con la Santa Sede de 1979. Sin embargo, este Consejo pidió un tratamiento transversal de los valores en todos los niveles educativos, lo cual supuso diluir lo esencial de la formación democrática al albur y buena voluntad de profesores no específicamente preparados ${ }^{45}$.

\footnotetext{
${ }^{41}$ Savater, Fernando, "La ética y su esperpento", en El País (3/6/1991).

${ }^{42}$ Savater, Fernando, "Inflación ética", El País (29/05/2013).

${ }^{43}$ Savater, Fernando, "Sin fe, ni fu ni fa", El País (11/03/2007).

${ }^{44}$ Savater, Fernando, “¿Ciudadanos o feligreses?”, El País (4/07/2007).

${ }^{45}$ Savater, Fernando, “Educación cívica: ¿transversal o atravesada?”, El País (1/03/2005).
} 
En Francia existe la Carta de laicidad en la escuela que es una admirable declaración de principios y deberes republicanos en cada una de las 55.000 escuelas públicas. En uno de sus puntos establece que el laicismo garantiza la libertad de conciencia, al contrario de España donde se avecina un revival del catecismo en nuestra educación con la ley Wert. Se trata de evitar todo proselitismo que impida la libre elección. En otro punto de esa Carta, se dice que los estudiantes tienen derecho a un acceso a la cultura común del país, cuya base es la lengua común. Esa lengua, en Francia, es la lengua vehicular de la enseñanza. En España, la posibilidad de que el español sea vehicular en todo el Estado, aunque las lenguas cooficiales lo sean también en sus respectivas autonomías, ha despertado la oposición de la izquierda. Para Savater, los devotos clericales creen que el laicismo va a acabar con las religiones, y los devotos separatistas suponen que quiere exterminar las lenguas regionales. De ahí la necesidad de explicar qué es el laicismo desde una asignatura como Educación para la Ciudadanía ${ }^{46}$.

\section{Bibliografía}

Ávila, R. (2006). Fernando Savater. El intelectual y su memoria. Granada: Editorial Universidad de Granada.

Barnatán, M. (1984). Fernando Savater contra el Todo. Madrid: Anjana Ediciones.

Nogueroles, M. (2013). Fernando Savater: biografia intelectual de un joven filosofo. Madrid, Endymion.

Revilla, A. "El discurso religioso de un ateo practicante: Fernando Savater". En: Cabria, JL, Sánchez-Grey, J (eds.). Dios en el pensamiento hispano del siglo XX. Salamanca, Sígueme, 2002, pp. 421-446.

Savater, F. (1970). Nibilismo y acción. Madrid: Taurus.

-(1975a). Escritos politeistas. Madrid: Editora Nacional.

-(1975b) De los dioses y del mundo. Valencia: Fernando Torres.

-(1976). La filosofía como anhelo de revolución. Madrid, Ayuso.

-(1977). La piedad apasionada. Salamanca:Sígueme.

-(21/03/1980). “Osadía clerical”. El País, Madrid.

-(1987). A decir verdad. Madrid, FCE.

${ }^{46}$ Savater, Fernando, "Laicismo y lengua común”, en El País (1/10/2013). 
-(1990). Humanismo Impenitente. Barcelona: Anagrama.

-(3/6/1991) "La ética y su esperpento". El País, Madrid.

-(1993). El jardin de las dudas. Barcelona: Planeta.

-(1995). La infancia recuperada. Madrid: Taurus.

-(22/4/1995) “Los requisitos de la tolerancia”. El País, Madrid.

-(1998). Despierta y lee. Madrid: Alfaguara.

-(2002). Ética y ciudadanía. Barcelona, Montesinos.

-(2002). Pensamientos arriesgados. (Casi) todo Savater. Madrid: La Esfera de los Libros.

-(2003). Mira por dónde. Autobiografia razonada. Madrid: Taurus.

-(4/07/2003) “Nuestras raíces cristianas". El País, Madrid.

-(2004). Las preguntas de la vida. Barcelona: Ariel.

-(19/01/2004). "Otras inquisiciones". El País, Madrid.

-(3/04/2004). "Laicismo: cinco tesis". El País, Madrid.

-(18/12/2004). “Tres actitudes morales”. El País, Madrid.

-(1/03/2005) "Educación cívica: ¿transversal o atravesada?”. El País, Madrid.

-(13/04/2005). "La globalización de Dios". El País, Madrid.

-(5/11/2005) "La laicidad explicada a los niños”. El País, Madrid.

-(11/02/2006). "Fanáticos sin fronteras". El País, Madrid.

-(21/04/2006) “Los demonios racionales". El País, Madrid.

-(12/08/2006). “En defensa propia”. El País, Madrid.

-(2007a) La vida eterna. Barcelona: Ariel.

-(2007b) Diccionario filosófico. Barcelona: Ariel.

-(11/03/2007). "Sin fe, ni fu ni fa”, El País, Madrid.

-(4/07/2007) “¿Ciudadanos o feligreses?”, El País, Madrid.

-(23/08/2007) "Instruir educando", El País, Madrid.

-(28/09/2007) "Del dicho al hecho", El País, Madrid.

-(8/12/2007) "El triunfo del libertinaje”, El País, Madrid.

-(2008) “¿Es tolerable la tolerancia religiosa?” Isegoría, 39, 22-23.

-(28/05/2008) "Regreso al futuro", El País, Madrid.

-(1/07/2008) "Los santos terribles", El País, Madrid. 
-(11/07/2008) “Ciudadanía y lengua común”, El Pais, Madrid.

-(16/10/2008) “Siempre negativa, nunca positiva”, El País, Madrid.

-(3/11/2008) “¿El final de la cordura?”, El País, Madrid.

-(27/04/2010) “Los velos en danza”, El País, Madrid.

-(10/09/2010) "La vacante de Dios”, El País, Madrid.

-(9/11/2010) “¿Hasta cuándo?”, El País, Madrid.

-(14/06/2011) "Iglesia y religión”, El País, Madrid.

-(29/05/2013) "Inflación ética”, El País, Madrid.

-(1/10/2013) “Laicismo y lengua común”, El País, Madrid.

-(9/12/2013) “Batalla de catecismos”, El País, Madrid.

Recibido: 26/12/2014

Aceptado: 16/03/2015

\section{(c) $6 \Theta$}

ENDOXA está bajo una licencia de Creative Commons Reconocimiento-NoComercial-SinObraDerivada 4.0 Internaciona 
